\title{
KOGNITIF BIDAN TERHADAP PEMERIKSAAN DIASTASIS RECTI PADA IBU NIFAS
}

\author{
Nurun Ayati Khasanah 1 , Ferilia Adiesti ${ }^{2}$, Citra Adityarini Safitri ${ }^{3}$ \\ 1,2,3 Program Studi Kebidanan Sekolah Tinggi IImu Kesehatan Majapahit \\ Email: nurun.ayati@gmail.com
}

\begin{abstract}
ABSTRAK
Diastasis rectus abdominis dapat terjadi kapanpun pada ibu hamil trimester dua, dampaknya pada ibu post partum yang mengalami diastasis rectus abdominis adalah melemahnya dinding abdomen, mengurangi kontraksi kekuatan otot abdomen dan kestabilan pelvis. Risiko seorang perempuan mengalami diastasis recti ini jauh lebih besar jika ukuran tubuhnya tergolong kecil, mengandung janin kembar, hamil pada usia 35 tahun ke atas, serta berat janin yang besar.Tujuan penelitian ini untuk mengetahui Hubungan kognitif terhadap pemeriksaan diastasis recti pada ibu nifas .Penelitian ini menggunakan pendekatan cross sectional. Populasi pada penelitian ini adalah seluruh tenaga kesehatan ( bidan ) di wilayah kerja UPT Puskesmas Bangsal Kabupaten Mojokerto. Sampel penelitian ini adalah sebagian tenaga kesehatan ( bidan ) yang ada di wilayah kerja UPT Puskesmas Bangsal Kabupaten Mojokerto, jumlah sampel 23 orang . pengambilan sampel pada penelitian adalah simple random sampling dilkasanakan pada bulan Agustus - November 2020. Instrumen pada penelitian menggunakan kuisioner, kemudian dianalisis secara univariat dan bivariat . untuk mengetahui hubungan menggunakan Analisis statistik Fisher's Exact Test. Berdasarkan hasil penelitian bahwa sebagian besar responden memiliki kognitif yang baik sebanyak 13 ( $56.53 \%)$ dan sebagian besar melakukan pemeriksaan diastasis recti sebanyak 17 ( 73.92\%) responden .Berdasarkan uji Analisis Fisher's Exact Test dengan tingkat kemaknaan $(\alpha<0.05)$ didapatkan nilai $(\alpha=0,022)$ menunjukkan bahwa ada hubungan kognitif dengan pemeriksaan diastasis recti pada ibu nifas .Pengetahuan didapat dari informasi sepanjang hidup seseorang. Pengetahuan tenaga kesehatan ( bidan ) tentang pemeriksaan diastasis recti yang mempengaruhi tenaga kesehatan ( bidan ) tersebut untuk melakukan pemeriksaan diastasis recti. Sebagai tenaga kesehatan seyogyanya selalu melakukan pemeriksaan diastasis recti pada ibu nifas yang datang kepelayanan baik di Rumah Sakit, Puskesmas maupun PMB
\end{abstract}

Kata Kunci: Kognitif Bidan , Pemeriksaan Diastasis Recti, Ibu Nifas

\begin{abstract}
Diastasis rectus abdominals can occur at any time in the second trimester of pregnancy, the impact on postpartum mothers who experience diastasis rectus abdominals is the weakening of the abdominal wall, reducing abdominal muscle strength contractions and pelvic stability. The risk of a woman experiencing diastasis recti is much greater if her body size is small, contains twin fetuses, is pregnant at the age of 35 years and over, and has a large fetal weight. This study used a cross-sectional approach. The population in this study were all health workers (midwives) in the working area of the UPT Puskesmas Bangsal, Mojokerto Regency. The sample of this research is some health workers (midwives) in the working area of UPT Puskesmas Bangsal Mojokerto Regency, the number of samples is 23 people. Sampling in the study was simple random sampling which was carried out in August - November 2020. The instrument in this study used a questionnaire, then analyzed univariately and bivariable. to find out the relationship using Fisher's Exact Test statistical analysis.Based on the results of the study that most of the respondents had good cognitive as many as 13 (56.53\%) and most of them did diastasis recti examination as many as $17(73.92 \%)$ respondents. $=0.022$ ) indicates that there is a cognitive relationship with diastasis recti examination in postpartum mothers.
\end{abstract}


Knowledge is obtained from information throughout a person's life. Knowledge of health workers (midwives) about diastasis recti examinations that affect the health workers (midwives) to perform diastasis recti examinations. As health workers, they should always carry out diastasis recti examinations for postpartum mothers who come to service both in hospitals, health centres and PMB.

\section{Keywords: cognitive midwife, diastasis recti examination, postpartum mothers}

\section{PENDAHULUAN}

Kehamilan merupakan peristiwa paling menakjubkan dalam kehidupan perempuan.

Selama kehamilan,perempuan mengalami berbagai hal mengejutkan, mulai keinginan makan di luar kebiasaan, perubahan warna kulit, pola makan, pola pikir, dan berat badan yang meningkat pesat. Semakin tua usia kehamilan, tekanan pada perut akan semakin kuat dan menyebabkan otot perut melebar ke kiri dan ke kanan sehingga menghasilkan jarak di bagian tengahnya ( Akram, 2014) . Kondisi ini bisa dialami ibu hamil di trimester ketiga maupun setelah persalinan, otot perut yang terpisah dapat menyebabkan munculnya tonjolan di tengah perut yang bisa dilihat saat otot perut tegang. Risiko seorang perempuan mengalami diastasis recti ini jauh lebih besar jika ukuran tubuhnya tergolong kecil, mengandung janin kembar, hamil pada usia 35 tahun ke atas, serta berat janin yang besar. Diastasis rectus abdominis dapat terjadi kapanpun pada ibu hamil trimester dua, dampaknya pada ibu post partum yang mengalami diastasis rectus abdominis adalah melemahnya dinding abdomen, mengurangi kontraksi kekuatan otot abdomen dan kestabilan pelvis (ulfah maria,2014).

Diastasis Recti Abdominal (DRA) paling sering terjadi pada ibu hamil karena kelemahan otot perut akibat pengaruh hormon ibu dan peningkatan peregangan rektus abdominis yang disebabkan oleh rahim yang membesar. Diastasis rectus abdominis berpeluang besar terjadi pada wanita dengan obesitas, kehamilan multipara, makrosomia janin, dan polihidramnion, panggul sempit karena selama kehamilan bayi akan ditemukan lebih ke posisi anterior (Mahalakshmi et all, 2016). Ukuran normal linea alba secara umum mempunyai lebar $15 \mathrm{~mm}$ pada proses xifoid, $22 \mathrm{~mm}$ pada $3 \mathrm{~cm}$ di atas umbilikus, dan $16 \mathrm{~mm}$ pada $2 \mathrm{~cm}$ di bawah umbilikus (Sanjivani. 2016).Tidak hanya itu, sembelit dan mengangkat barang yang berat juga dapat meningkatkan risiko diastesis. Selama kehamilan, dinding uterus berubah menjadi jauh lebih tebal dan lebih lunak, pada usia hamil cukup bulan uterus menjadi seperti sebuah kantong muskuler dengan dinding yang lunak, mudah menekuk dan ketebalan 0,5$1 \mathrm{~cm}$ atau kurang. Karena ada komplikasi muskuloskeletal setelah DRA, ada kebutuhan untuk menerapkan latihan 
korektif DRA dalam mencegah atau mengobati DRA setelah kelahiran anak. Salah satu tanda dan gejala khas yang mungkin dirasakan ketika mengalami diastasis recti adalah pembengkakan atau ada jarak antara garis tengah perut. Selain itu, ada keluhan nyeri pada punggung bagian bawah, rasa sakit pada panggul, serta batuk atau bersin berbarengan dengan keluarnya urine (yang tidak terkendali atau tidak disadari). Setelah melahirkan, hormon tubuh akan kembali ke kondisi sebelum kehamilan, tetapi elastisitas jaringan otot perut jadi berkurang. Pada wanita dengan diastasis rekti, kondisi perut tidak dapat kembali seperti semula akibat pelebaran otot yang berlebihan selama hamil, sehingga perut masih terlihat buncit.(Fairus martini ,2019)

Pelebaran otot perut selama kehamilan dapat ditandai dengan nyeri pada punggung bagian bawah, panggul yang terasa sakit, serta urine yang keluar saat bersin maupun batuk. Garis pada bagian tengah perut yang semakin terlihat juga bisa menandakan bahwa sedang terjadi pelebaran pada otot perut .Meskipun tergolong lazim, diastasis rekti juga memiliki risiko komplikasi yang tidak boleh dianggap remeh. Selain membuat perut terlihat buncit meski sudah tidak hamil, diastasis rekti juga dapat memudahkan timbulnya hernia. Latihan fisik ringan memang dapat meringankan, latihan pernapasan serta yoga dinilai lebih efektif dalam melatih otot perut agar kembali kuat efek diastasis rekti, Untuk beberapa perempuan, diastasis recti bisa sembuh dengan sendirinya setelah melahirkan karena otot perut mendapatkan kembali kekuatannya. Bila masih merasakan gejala atau otot perut masih terpisah 8 minggu setelah persalinan.

Diastasis recti dialami oleh ibu hamil, sekitar $90 \%$ ibu hamil yang memiliki diastasis recti. Literatur internasional menunjukkan nilai dari prevalensi diastasis rekti abdominalis ini adalah 35\% - 100\% . Di Indonesia belum mendapatkan angka kejadian diastasis rectus abdominis. Berdasarkan hasil penelitian, yang dilakukikan oleh , (Nurmawati, 2014) yang dilakukan selama enam bulan postpartum, ditemukan $39 \%$ wanita dengan diastasis rectus abdominis.( Estiani M, Aisyah, 2018). Cara memeriksa diastasis recti dengan tidur secara terlentang dengan lutut ditekuk dan telapak kaki berada di lantai. Lalu letakkan tangan di perut dengan posisi jari yang mengarah ke bawah. Dengan lembut, tekan jari di daerah pusar, lalu secara perlahan angkat kepala sehingga dagu mengarah ke dada. Posisi ini akan membuat rectus abdominis berkontraksi. Jika merasakan jarak selebar dua jari atau lebih di antara otot, ketika otot berkontraksi, positif diastasis rekti. Jarak di antara otot rectus abdominis tersebut dapat berkisar antara 1 hingga 10 jari. Selain mengukur jarak, perlu mengukur kedalamannya Hidayah , 2019)

Ernawati , 2013 telah melakukan Penelitian tentang penggunaan penggunaan stagen terhadap diastasis 
rectus abdominis ibu post partum dimana penelitian dilakukan di Rumah Bersalin Hasanah wilayah Gemolong Sragen, pada 36 ibu post partum. Penggunaan stagen atau korset dapat membantu mengurangi rasa sakit di punggung saat melakukan aktivitas pada ibu nifas. Penelitian juag dilakukan oleh Murti Girinda, 2015 adanya korelasi antara senam nifas dengan pemulihan otot perut (diastasis rectus abdominis) pada ibu postpartum. Diastasis rekti abdominal sering tidak terdeteksi dan juga tidak dilakukan pemeriksaan oleh tenaga kesehatan. Penelitian yang dilakukan Amalia Rizki , 2019 dengan judul Ketrampilan Bidan terhadap pemeriksaan derajat diastasis rekti abdominalis pada ibu nifas" dimana hasilnya menunjukkan bahwa bidan belum pernah mendapatkan pelatihan atau sosialisasi tentang pemeriksaan derajat diastasis rekti abdominalis pada ibu nifas dan selama ini tidak pernah melakukan pemeriksaan diastasis rekti Abdominalis pada ibu nifas, bidan belum mengetahui tujuan dan manfaat dari pemeriksaan derajat diastasis rekti abdominalis pada ibu nifas.

Berdasarkan alasan diatas perlu dilakukan penelitian tentang Kognitif Bidan Terhadap Pemeriksaan Diastasis Recti Pada Ibu Nifas di wilayah kerja UPT Puskesmas Bangsal Kabupaten Mojokerto.

\section{METODE}

Penelitian ini menggunakan pendekatan cross sectional yaitu penelitian yang menekannkan pada hubungan antara variabel independen denga variabel dependen yang waktu pengumpulan dilakukan dalam waktu sekali saja ( Nursalam, 2016 JPenelitian ini dilaksanakan di wilayah kerja UPT Puskesmas Bangsal Kabupaten Mojokerto. Populasi pada penelitian ini adalah seluruh tenaga kesehatan ( bidan ) di wilayah kerja UPT Puskesmas Bangsal Kabupaten Mojokerto. Sampel penelitian ini adalah sebagian tenaga kesehatan ( bidan ) yang ada di wilayah kerja UPT Puskesmas Bangsal Kabupaten Mojokerto jumlah sampel 23 orang dan pengambilan sampel pada penelitian ini adalah simple random sampling.penelitian dilkasanakan pada bulan Agustus - November 2020. kreteria inklusi dalam penelitian ini adalah tenaga kesehatan ( bidan ) di wilayah kerja UPT Puskesmas Bangsal yang bersedia menjadi responden. Sedangkan kreteria Eksklusi dalam penelitian ini tenaga kesehatan (bidan) yang tidak bersedia menjadi responden . instrumen pada penelitian menggunakan kuisioner, kemudian dianalisis secara univariat dan bivariat . untuk mengetahui hubungan Kognitif tentang pemeriksaan diastasis recri terhadap pemeriksaan diastasis recti di wilayah UPT Puskesmas Bangsal kabupaten mojokerto. Analisis statistik yang digunakan adalah Fisher's Exact Test.

\section{HASIL PENELITIAN}

$\begin{array}{lll}\text { Distribusi } & \text { Frekuensi } & \text { Responden } \\ \text { berdasarkan usia di UPT } & \text { Puskesmas } \\ \text { Bangsal mojokerto } 2020 & \end{array}$


Tabel 4.1 Distribusi Frekuensi Responden Berdasarkan Usia di UPT Puskesmas Bangsal Mojokerto 2020
Berdasarkan tabel diatas menunjukkan bahwa sebagian besar responden memiliki kognitif yang baik sebanyak 13 ( $56.53 \%$ ) responden

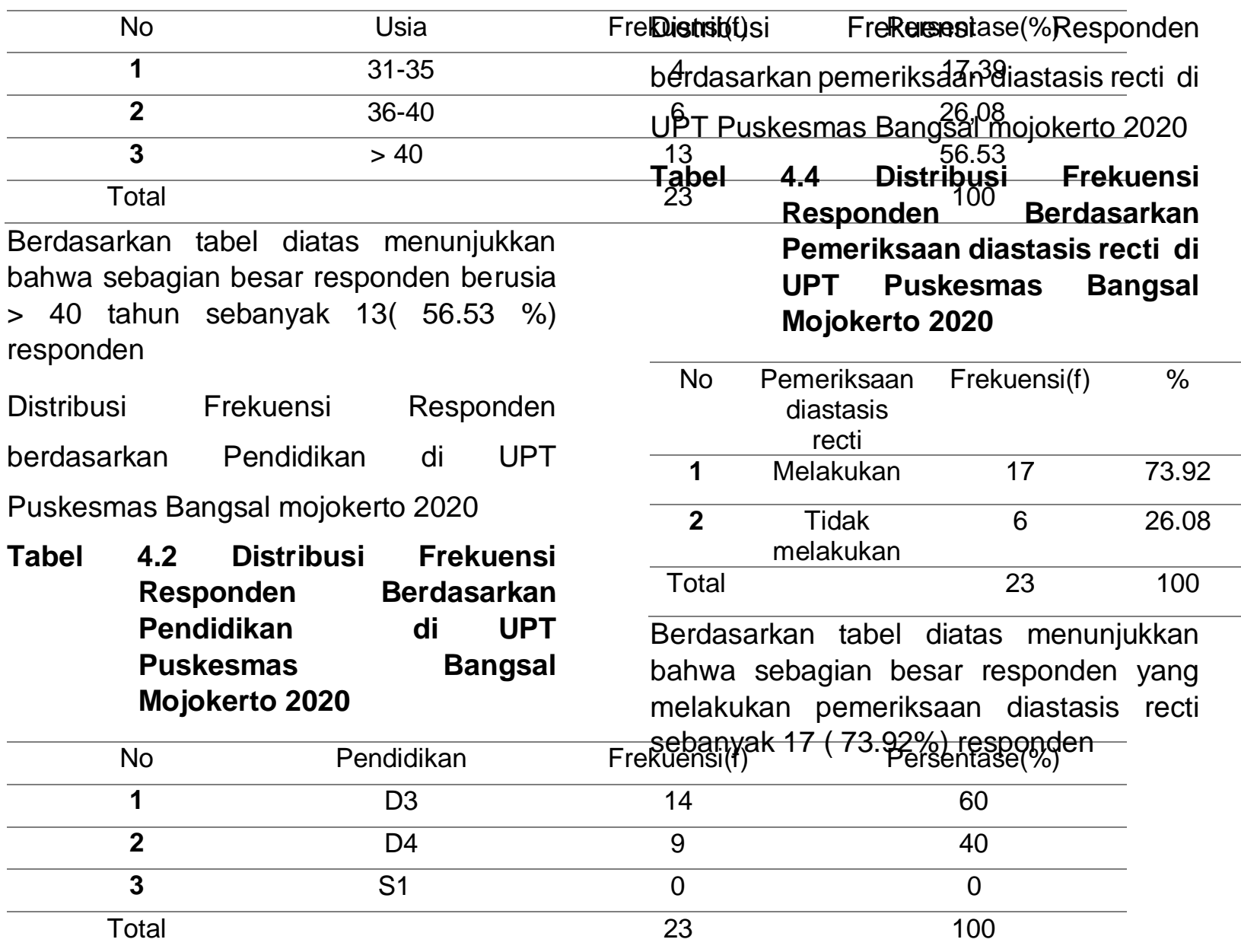

Berdasarkan tabel diatas menunjukkan bahwa sebagian besar responden berpendidikan D3 tahun sebanyak 14( 60 \%) responden

Distribusi Frekuensi Responden berdasarkan Kognitif di UPT Puskesmas Bangsal mojokerto 2020

\section{Tabel 4.3 Distribusi Frekuensi Responden Berdasarkan Kognitif di UPT Puskesmas Bangsal Mojokerto 2020}

\begin{tabular}{cccc}
\hline No & Kognitif & Frekuensi(f) & $(\%)$ \\
\hline $\mathbf{1}$ & Baik & 13 & 56.53 \\
\hline $\mathbf{2}$ & Kurang & 10 & 43.47 \\
\hline Total & & 23 & 100
\end{tabular}


Tabel 4.5 hubungan kognitif diastasis recti dengan pemeriksaan Pemeriksaan diastasis recti Pada lbu Nifas Di di UPT Puskesmas Mojokerto 2020

\section{Pemeriksaan diastasis recti}

\begin{tabular}{ccccccc} 
Kognitif & \multicolumn{2}{c}{$\begin{array}{c}\text { Tidak } \\
\text { melakukan }\end{array}$} & \multicolumn{2}{c}{ Melakukan } & \multicolumn{2}{c}{ Total } \\
Baik & 2 & $\begin{array}{c}8.69 \\
\%\end{array}$ & 11 & $\begin{array}{c}47.82 \\
\%\end{array}$ & 13 & $\begin{array}{c}56.5 \\
3 \%\end{array}$ \\
\hline Kurang & 4 & $\begin{array}{c}17.39 \\
\%\end{array}$ & 6 & $\begin{array}{c}26.0 \\
\%\end{array}$ & 10 & $\begin{array}{c}43.4 \\
7 \%\end{array}$ \\
\hline Total & 6 & $51.9 \%$ & 17 & $48.1 \%$ & 23 & $\begin{array}{c}100 . \\
0 \%\end{array}$ \\
\hline
\end{tabular}

Berdasarkan tabel diatas menunjukkan responden dengan kognitif baik 11 ( 47.82\%) melakukan pemeriksaaan diastasiss recti sedangkan kognitif kurang 6 ( 26.0\%). melakukan pemeriksaan diastasis recti . Berdasarkan uji Analisis Fisher's Exact Test dengan tingkat kemaknaan $(\alpha<0.05)$ didapatkan nilai $(\alpha=0,022)$ menunjukkan bahwa ada hubungan kognitif dengan pemeriksaan diastasis recti pada ibu nifas .

\section{PEMBAHASANAN}

Hasil penelitian yang ditunjukkan dengan Distribusi Frekuensi tenaga kesehatan ( bidan ) berdasarkan usia di dapatkan sebagian besar responden berusia > 40 tahun sebanyak 13 ( $56.53 \%$ ) responden tenaga kesehatan ( bidan ) yang memiliki usia lebih tua belum tentu memiliki kemauan untuk melakukan pemeriksaan diastasis recti, begitu pula sebaliknya tenaga kesehatan ( bidan ) yang berusia lebih muda juga belum memiliki kemauan melakukan pemeriksaan diastasis recti. Pada tenaga kesehatan ( bidan ) di wilayah UPT Puskesmas Bangsal, usia bukanlah variabel yang berpengaruh terhadap pemeriksaan diastasis recti.

Distribusi Frekuensi Responden berdasarkan Pendidikan sebagian besar responden berpendidikan D3 tahun sebanyak $14(60 \%)$. Faktor yang mempengaruhi pendidikan salah satunya adalah tingkat pendidikan, dalam penelitian ini didapatkan mayoritas tenaga kesehatan adalah lulusan D3 sebanyak 14 ( 60\%) . Menurut Notoatmodjo (2014) tingkat pendidikan seseorang berpengaruh pada kemapuan berfikir, seseorang akan berfikir lebih rasional mampu menguraikan dalam mengakap informasi salah satunya dipengaruhi tingkat pendidikan. Salah satu factor yang mempengaruhi pendidikan adalah factor eksternal yakni informasi, social, budaya dan lingkungan. Pengetahuan tidak hanya didapatkan dari jenjang pendidikan yang ditempuh namun juga didukung dari informasi yang diterima misal dari media masa, koran, majalah, internet, televisi. Selain itu motivasi juga mempengaruhi pengetahuan seseorang, karena akan meningkatkan rasa ingin tahu terhadap sesuatu, rasa ingin tahu yang semakin meningkat akan memotivasi seseorang untuk mencari sumber informasi. Pendidikan seseorang 
dapat mempengaruhi pemahaman dari seseorang tersebut atas suatu prosedur, maka semakin tinggi pendidikan tenaga kesehatan ( bidan), maka semakin banyak informasi dan pengetahuan dimiliki sehingga kepatuhan semakin tinggi. Di wilayah kerja UPT puskesmas pendidikan tenaga kesehatan ( bidan ) mayoritas D3, pendidikan D3 kebidanan merupakan pendidikan sayarat utama untuk tenaga bidan bisa melakukan pelayanan kebidanan baik dipelayanan Puskesmas, Rumah Sakit maupun PBM untuk saat ini.

Dari 23 tenaga kesehatan di wilayah kerja UPT Puskesmas bangsal yang melalukan pemeriksaan diastasis recti adalah dengan kognitif baik 11 ( 47.82\%) sedangkan kognitif kurang 6 ( $26.0 \%)$ melakukan pemeriksaan diastasis recti sesuai dengan penjelasan dari Sukesi ,2020) menyatakan bahwa setiap orang mempunyai kognitif ( pengetahuan) dan setiap orang mempunyai kognitif yang berbeda- beda, secara umum tingkat pengetahuan ( kognitif ) seseorang meliputi, yaitu : Tahu ( Know), Memahami (Comprehansif ), Aplikasi (Aplication), Analisis (Analysis ), Sintesis ( Syntesis ) serta Evaluasi (Evaluation) . komponen komponen tesebut menunjang sikap seseorang Untuk memperoleh pengetahuan. Banyak cara yang dilakukan untuk meningkatkan pengetahuan antara lain mengikuti seminar, mengikuti pelatihan, meningkatkan pendidikan. Ada beberapa faktor yang mempengaruhi seseorang dalam melalukan suatu tindakan antara lain: pengaruh orang lain , pengalaman pribadi, pengaruh kebudayaan,lembaga pendidikan, media massa, lembaga agama serta faktor emosi ( Azwar,2013).

Dampak bagi seseorang yang berwawasan luas adalah perubahan perilaku sesuai dengan teori yang dijelaskan oleh Notoadmojo dalam Rajaratenam dkk ( 2014) bahwa semakin baik pengetahuan seseorang, semakin baik pula perilakunya. Domain perilaku meliputi pengetahuan, sikap dan tindakan, dimana hal ini menunjukkan bahwa seseorang yang memiliki suatu pengetahuan harus menyikapinya dan melakukannya ke dalam suatu tindakan yang sering disebut perilaku. Pengetahuan merupakan segalanya yang terjadi di dalam kehidupan sehari-hari seseorang.Sikap merupakan respon atau reaksi yang belum terbuka dari seseorang terhadap suatu obyek atau stimulus. Sikap tidak bisa dilihat secara langsung hanya bisa ditafsirkan sebelum dari perilaku seseorang yang tertutup. Sikap secara nyata menunjukkan konotasi adanya kesesuaian reaksi terhadap stimulus tertentu. Hal ini menunjukkan bahwa sikap tertutup hanya terlihat apabila adanya suatu tindakan yang diperlihatkan seseorang. Sikap merupakan kesiapan atau kesediaan seseorang untuk bertindak dan bukan merupakan pelaksanaan motif tertentu. Dengan kata lain fungsi sikap belum merupakan tindakan atau aktifitas, akan tetapi merupakan predisposisi 
perilaku atau tindakan. Ini menunjukkan bahwa domain perilaku merupakan satu kesatuan dari pengetahuan, sikap dan tindakan (aktifitas).

Tenaga kesehatan ( bidan ) melaukan pemeriksaan diastasis recti karena mengetahui pentingnya pemeriksaan tersebut dilakukan pada ibu nifas untuk mengurangi risiko komplikasi yang tidak boleh dianggap remeh. Selain membuat perut ibu nifas terlihat buncit meski sudah tidak hamil, diastasis rekti juga dapat memudahkan timbulnya hernia pada ibu nifas. Latihan fisik ringan memang dapat meringankan, latihan pernapasan serta yoga dinilai lebih efektif dalam melatih otot perut agar kembali kuat efek diastasis rekti, Untuk beberapa perempuan, diastasis recti bisa sembuh dengan sendirinya setelah melahirkan karena otot perut mendapatkan kembali kekuatannya. Bila masih merasakan gejala atau otot perut masih terpisah 8 minggu setelah persalinan.

\section{KESIMPULAN}

Berdasarkan hasil penelitian dapat disimpulkan bahwa pengetahuan dapat mempengaruhi perilaku seseorang. pengetahuan didapat dari informasi sepanjang hidup seseorang. Pengetahuan tenaga kesehatan ( bidan ) tentang pemeriksaan diastasis recti yang mempengaruhi tenaga kesehatan ( bidan) tersebut untuk melakukan pemeriksaan diastasis recti.

\section{Daftar pustaka}

Akram, J. and Matzen, S. H. (2014) .Rectus abdominis diastasis', Journal of Plastic Surgery and Hand Surgery, 48(3), pp. 163-169. doi: 10.3109/2000656X.2013.85 9145.

Amalia Rizki ( 2019 ) Ketrampilan Bidan Dalam Melakukan Pemeriksaan DerajaT Diastasis Rekti Abdominalis Pada lbu Nifas. Journal For Quality In Women's Health | Vol. 2 No. 2 September 2019 | Pp. 38 - 42 P-ISSN: 26156660 | E-ISSN: 2615-6644 DOI: 10.30994/Jqwh.V2i2.36

Azwar S. (2013). Sikap Manusia: Teori dan Pengukurannya. Yogyakarta: Pustaka Pelajar

Estiani M, Aisyah ( 2018) Faktor - Faktor Yang Berhuungan Dengan Kejadian Diastasis Recti Abdominalis Pada Ibu Post Partum Diwilayah Kerja UPTD Puskesmas Sukaraya Baturaja, Jurnal Keperawatan Sriwijaya, Volume 5 - Nomor 2, Juli 2018,ISSN No 23555459 Hall 24-31

Fairus martini (2019) Peregangan Abdomen Selama Kehamilan Meningkatkan

\section{Diastasis}

RectusAbdominus, Jurnal Kesehatan Metro Sai Wawai Volume 12 No

2, Desember 2019, 27-32

Fitriahadi, Daryanti (2020). Dance Pregnancy Berpengaruh Menurunkan Diastasis Recti Pada lbu Hamil Di Bpm Kabupaten Sleman Yogyakarta Midwifery Journal | Vol. 5, No. 1, Januari 2020, hal 45-51

Hidayah N, Listyani K( 2019) The Effect of Postpartum Gymnastics 
on the Size of Abdominal

Diastasis Rectus in Normal

Postpartum. Advances in

Health

Sciences

Research, volume 27 hall 212-214

Mahalakshmi, et all ( 2016) Effect of exercise on diastasis recti abdominis

$$
\begin{aligned}
& \text { among the primiparous } \\
& \text { women: a quasi- } \\
& \text { experimental study. } \\
& \text { International Journal of } \\
& \text { Reproduction, } \\
& \text { Contraception, Obstetrics } \\
& \text { and Gynecology } \\
& \text { Volume } 5 \text {. Issue 12: 4441- } \\
& 4446
\end{aligned}
$$

Murti Girinda ( 2015) Korelasi Senam Nifas Dengan Pemulihan Otot Perut (Diastasis

$$
\begin{aligned}
& \text { Rectus Abdominis) Pada } \\
& \text { Ibu Post Partum.Jurnal } \\
& \text { Fisioterapi }
\end{aligned}
$$

Notoatmodjo, S.2014. IImu Perilaku Kesehatan. Jakarta: Rineka Cipta

Nurmawati eka et all, ( 2014) Manfaat Penguatan Otot Transversus Abdominis Dan Muscle Pumping Ekstremitas Inferior Terhadap Diastasis Recti Abdominis Pada Ibu Nifas Jurnal IImiah Kebidanan, Vol. 5 No. 1 Edisi Juni 2014, hlm. 94-102

Nursalam. (2016). Metodologi Penelitian IImu Keperawatan. Pendekatan Praktis Edisi: 4 .Jakarta : Selemba Medika

Sanjivani Ramesh Khandale1, Deepali Hande2 Effects of Abdominal Exercises on Reduction of Diastasis Recti in Postnatal Women. International Journal of Health Sciences \&
Research (www.ijhsr.org) 184 Vol.6; Issue: 6; June 2016

Sukesih eet all (2020) Pengetahuan Dan Sikap Mahasiswa

Kesehatan Tentang

Pencegahan Covid-19 Di Indonesia. Jurnal IImu Keperawatan dan Kebidanan

Vol.11No.2(2020)258-264

Ulfah Maria ( 2014) Hubungan Diastasis Recti Abdominis Dengan Nyeri Punggung

Bawah Pada lbu Hamil. Jurnal IImiah Kebidanan, Vol. 5 No. 2 Edisi Desember 2014, HIm. 6066 